Review Article

\title{
Drugs used in postoperative care of bypass surgery- An overview
}

\author{
Mirza Shiraz Baig ${ }^{a}$," Kishore Sonkusare ${ }^{b}$, Prakashchandra Rambhau Gade ${ }^{c}$
}

\begin{abstract}
${ }^{a}$ Department of Pharmacology, Govt. Medical College, Aurangabad 431001 (MS), India, ${ }^{b}$ Medical Advisor, Intas Pharmaceutical Ltd., Ahmedabad, India,

${ }^{\mathrm{c}}$ Department of Pharmacology, MIMSR, Latur (MS), India
\end{abstract}

\author{
Received: 7 October 2012 \\ Revised: 15 October 2012 \\ Accepted: 23 October 2012 \\ *Correspondence to: \\ Dr. Mirza Shiraz Baig, \\ Email: shirazdoctor@yahoo.com
}

\begin{abstract}
Postoperative care of cardiac surgical patients have shown important changes parallel to the surgical improvements in recent years. The post-operative approach to these patients is best directed by dividing their problems into the systems like cardiovascular care, Bleeding-Thrombosis and Transfusion Strategies, CNS care, Respiratory \& renal care, Postoperative pain and sedation management and lastly managing complications if any. The present article explains the drugs as therapeutic agents used in management of post-operative bypass surgery.
\end{abstract}

Keywords: Drugs, Postoperative, CABG

\section{INTRODUCTION}

Postoperative care of cardiac surgical patients have shown important changes parallel to the surgical improvements in recent years. These changes have resulted in intensive care unit (ICU) containing a greater proportion of older, sicker patients who have undergone more major surgery. The main determining factors of success of a cardiac operation are the events that occur within the operating room. However, some patients, who are very ill upon arrival in the ICU, may have a good long-term prognosis when postoperative care is meticulously provided. Conversely, patients who are doing well as they leave the operating room may be put at significant risk for complications by poor postoperative management. It is crucial in all circumstances, an expert interdisciplinary postoperative approach should be provided 24 hours a day in order to ensure a successful outcome. The postoperative cardiac surgical patient is in a special biologic situation due to the effects of CPB. Early after the operation there is a whole body inflammatory response with leaky capillaries and all its possible attendant problems. The physician must be keenly aware of this basic premise in caring for these patients. ${ }^{1}$

The post-operative approach to these patients is best directed by dividing their problems into the systems:

\section{Hemodynamic Management}

Medications are used perioperatively to provide vasoconstriction, venous and arterial vasodilation, and inotropic support as well as to treat arrhythmias. As summarized in Table $1 \& 2$ many of the commonly used medications have multiple actions. Selection of appropriate agents depends on accurate hemodynamic assessment.

\section{Pressors}

- They are indicated for vasodilated patients who have normal pump function and are unresponsive to volume.

- These agents include alpha agonist agents (e.g. neosynephrine) and vasopressin. Methylene blue has demonstrated efficacy in vasopressor-resistant hypotension.

- Pressors can contribute to peripheral ischemia and vasospasm of coronary arteries and arterial conduits.

- Careful monitoring of extremity perfusion and electrocardiographic changes is required when using these agents. ${ }^{2,3}$

\section{A) CARDIOVASCULAR CARE}


Table 1: Commonly used vasoactive drugs and hemodynamic effects.

\begin{tabular}{|c|c|c|c|c|c|c|}
\hline Pharmacologic agent & HR & PCW & CI & SVR & MAP & $\mathbf{M V}_{\mathrm{O} 2}$ \\
\hline \multicolumn{7}{|l|}{ Inotropic agents } \\
\hline Dobutamine & $\uparrow \uparrow$ & $\downarrow$ & $\uparrow$ & $\downarrow$ & $\uparrow \downarrow$ & $\uparrow \leftrightarrow$ \\
\hline Milrinone & $\uparrow$ & $\downarrow$ & $\uparrow$ & $\$ \downarrow$ & $\downarrow$ & $\uparrow \downarrow$ \\
\hline \multicolumn{7}{|l|}{ Mixed vasoactive agents } \\
\hline Epinephrine & $\uparrow \uparrow$ & $\uparrow \downarrow$ & $\uparrow$ & $\uparrow$ & $\uparrow$ & $\uparrow$ \\
\hline Norepinephrine & $\uparrow \uparrow$ & $\uparrow \uparrow$ & $\uparrow$ & $\uparrow \uparrow$ & $\uparrow \uparrow$ & $\uparrow$ \\
\hline Dopamine & $\uparrow \uparrow$ & $\uparrow \downarrow$ & $\uparrow$ & $1+$ & $\uparrow \downarrow$ & $\uparrow$ \\
\hline \multicolumn{7}{|l|}{ Vasopressor agents } \\
\hline Phenylephrine & $\leftrightarrow$ & $\uparrow$ & $\leftrightarrow$ & $\uparrow \uparrow$ & $\uparrow \uparrow$ & $\dagger \leftrightarrow$ \\
\hline Vasopressin & $\leftrightarrow$ & & $\leftrightarrow$ & $\uparrow \uparrow$ & $\uparrow \uparrow$ & $\uparrow \leftrightarrow$ \\
\hline Methylene blue & $\leftrightarrow$ & & $\leftrightarrow$ & $\uparrow$ & $\uparrow$ & $\uparrow$ \\
\hline \multicolumn{7}{|l|}{ Vasodilating agents } \\
\hline Nitroglycerin & $\uparrow$ & $\downarrow \leftrightarrow$ & $\leftrightarrow$ & $\downarrow$ & $\downarrow$ & $t_{\leftrightarrow}$ \\
\hline Nitroprusside & $\uparrow \uparrow$ & $\downarrow$ & $\leftrightarrow$ & $\downarrow \downarrow$ & $\downarrow \downarrow$ & $\downarrow \leftrightarrow$ \\
\hline Nicardipine & $\leftrightarrow$ & $\leftrightarrow$ & $\leftrightarrow$ & $\downarrow \downarrow$ & $\downarrow \downarrow$ & $\leftrightarrow$ \\
\hline Nesiritide & $\leftrightarrow$ & $\downarrow \leftrightarrow$ & $\leftrightarrow$ & $\downarrow$ & $\downarrow$ & $\leftrightarrow$ \\
\hline
\end{tabular}

*HR-Heart Rate, PCW- Pulmonary Wedge Capillary Pressure, CI- Cardiac Index, MAP- Mean Arterial Pressure, MV $_{\mathrm{O}^{-}}$ Mixed Venous Oxygen Saturation.

Table 2: Common ICU Scenarios and Management Strategies.

\begin{tabular}{|c|c|c|c|c|c|}
\hline \multicolumn{7}{|c|}{ Cardiac output syndromes } \\
\hline MAP & CVP & CO & PCW & SVR & Strategy \\
\hline Normotensive & High & Low & High & N/high & $\begin{array}{c}\text { Venodilator/diuretic/ } \\
\text { inotrope }\end{array}$ \\
\hline Hypertension & High & N & High & High & Vasodilator \\
\hline Hypotension & Low & Low & Low & N & Volume \\
\hline Hypotension & High & Low & High & High & Inotrope /Vasodilator \\
\hline Hypotension & N/ low & N / high & N / low & Low & $\alpha$ agonists \\
\hline
\end{tabular}

*CVP- Central Venous Pressure, CO- Cardiac Output, PCW- Pulmonary Capillary Wedge Pressure, SVR- Systemic Vascular Resistance.

\section{Vasodilators}

- They are indicated for hypertensive patients and for patients who are normotensive with poor pump function.

- Nitroglycerin and sodium nitroprusside are used commonly in the immediate postoperative period. Both have the advantage of being short acting and easy to titrate. Both can cause hypoxia by inhibiting pulmonary arterial hypoxic vasoconstriction and increasing blood flow through poorly oxygenated lung.
- Nitroglycerin is a stronger venodilator than an arterial dilator and can increase intercoronary collateral blood flow, but patients quickly can become tachyphylactic. Prolonged nitroprusside use can lead to cyanide toxicity, and methemoglobin levels must be monitored.

- Nicardipine is a calcium channel blocker with minimal effects on contractility or atrioventricular (AV) nodal conduction; it appears to have the efficacy of sodium nitroprusside (nipride) without its toxicity.

- Nesiritide, or brain natriuretic peptide, promotes diuresis in addition to vasodilation and may have 
beneficial lusitropic effects in patients with diastolic dysfunction.

\section{Beta blockers}

- Hypertension also can be treated with beta blockers. These agents work by decreasing heart rate and contractility.
- Esmolol is useful in the presence of labile blood pressure because of its short half-life.

- Labetalol combines beta- and alpha-adrenergic blockade.

- $\quad$ Patients whose pump function is inotrope-dependent should not receive beta blockers.

Flow chart 1: Management scheme for cardiovascular dysfunction in the post bypass period.

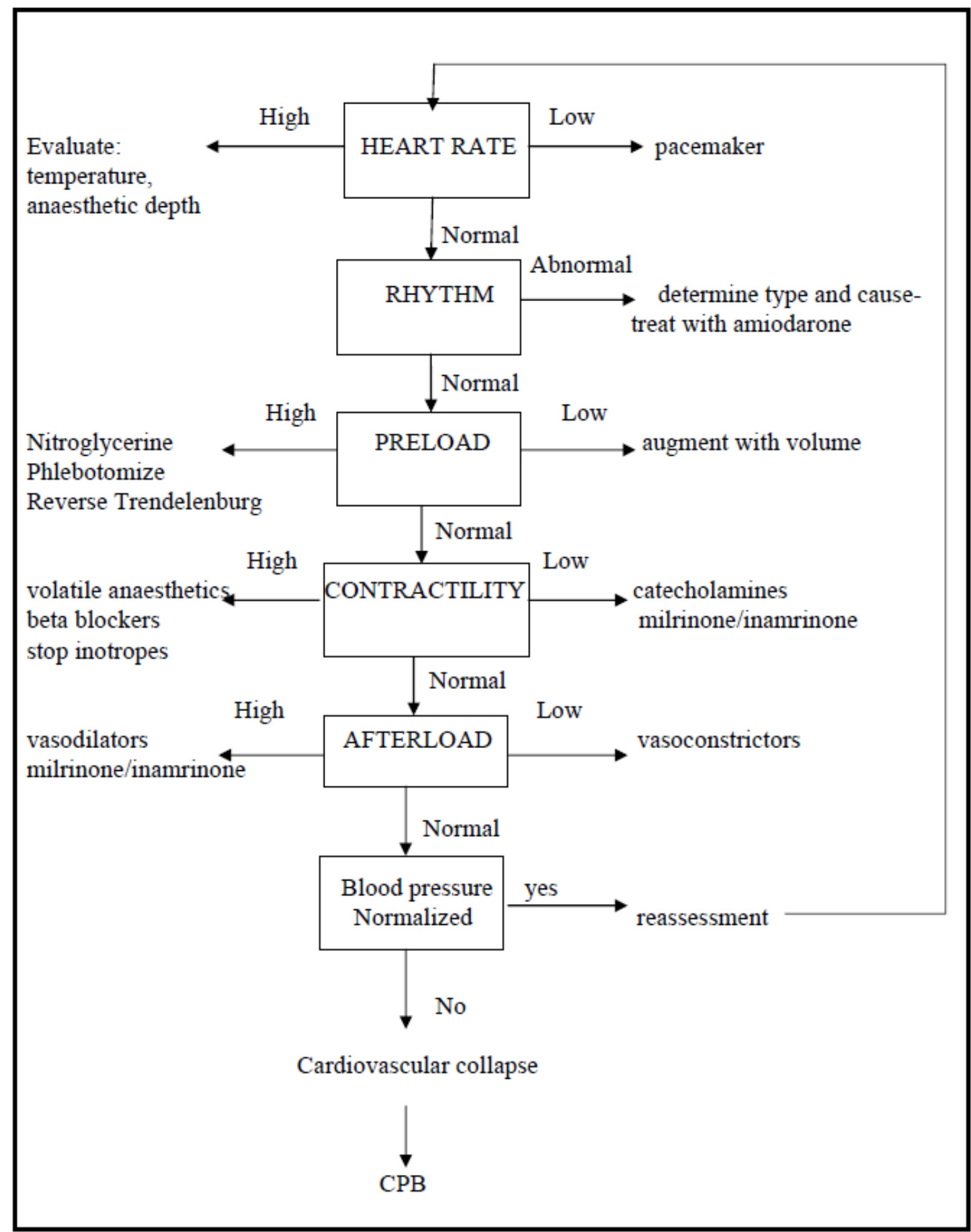




\section{Inotropic agents}

- Indicated when low cardiac output persists despite optimization of fluid status (preload) and vascular tone (afterload). These agents include betaadrenergic agents (e.g., dobutamine) and cyclic nucleotide phosphodiesterase inhibitors (e.g., milrinone). Both these agents increase cardiac output by increasing myocardial contractility and reducing afterload through peripheral vasodilation.

- Dobutamine is shorter acting and easier to titrate; milrinone achieves increases in cardiac output with lower myocardial oxygen consumption. ${ }^{4}$

- Both are arrhythmogenic and can exacerbate coronary ischemia. Both epinephrine and norepinephrine combine betaand alpha-adrenergic agonist effects; they are pressors in addition to positive inotropes.

- Dopamine in low doses causes splanchnic and renal vasodilation. Since perioperative beta blockade has been shown to improve mortality and morbidity following cardiac surgery, it seems reasonable to avoid the gratuitous use of inotropes, and efforts should be made to wean these agents rapidly when they are no longer required.

\section{Heart Rate and Rhythm Management}

\section{Ventricular arrhythmias}

Nonsustained ventricular tachycardia (VT) is common following cardiac surgery and typically a reflection of perioperative ischemia-reperfusion injury, electrolyte abnormalities (typically hypokalemia and hypomagnesemia), or an increase in exogenous or endogenous sympathetic stimulation.

Treatment:

- $\quad$ Sustained VT (persisting for more than 30 seconds or associated with significant hemodynamic compromise) requires more aggressive treatment.

- $\quad$ Ongoing ischemia should be ruled out (with coronary angiography if necessary).

- Electrolytes should be replaced, and inotrope should be minimized.

- Beta blockers, amiodarone, and lidocaine are useful therapies.

- Electrocardioversion should be employed if sustained VT causes significant compromise.

\section{Atrial fibrillation and flutter}

- Atrial fibrillation and flutter occur in 20 to $40 \%$ of patients undergoing coronary artery bypass grafting $(\mathrm{CABG})$ and generally is more common in patients undergoing valve and combined procedures.

- Beta blockers are the most commonly used and effective prophylactic treatment and should be started or resumed as soon as they can be tolerated safely following surgery.

- Beta blockers (sotalol) confer benefits other than atrial fibrillation prophylaxis, are easy to titrate, and do not have the toxicities associated with amiodarone. ${ }^{5}$

Treatment:

Reduces the incidence of AF and decreases the disruption and anxiety that it creates.

The principal premise of this strategy is recognition of the fact that for most patients with new-onset atrial fibrillation, the arrhythmia is self-limited (within 6 to 8 weeks independent of treatment approach).

\section{Drug therapy}

Agents can be divided conveniently into rate-control and rhythm-control agents, although beta blockers are also effective in converting atrial fibrillation postoperatively. Monodrug therapy generally is better than polydrug therapy.

\section{Rate-control agents:}

a. Beta blockers. Metoprolol should be first-line therapy in most patients and can be given orally or intravenously. Metoprolol should be titrated to effect with a heart rate goal of less than 100 beats per minute at rest. The suggested treatment for new-onset atrial fibrillation is $50 \mathrm{mg} \mathrm{PO}$, followed by $25 \mathrm{mg}$ PO until normal sinus rhythm (NSR) or adequate rate control is achieved, up to eight doses. Some patients may require over $400 \mathrm{mg} / \mathrm{d}$.

b. Calcium channel blockers. Diltiazem is the agent of choice. It should be initiated as a bolus at $0.25 \mathrm{mg} / \mathrm{kg}$ $\mathrm{IV}$, followed by $0.35 \mathrm{mg} / \mathrm{kg} \mathrm{IV}$, followed by a continuous infusion of 5 to $15 \mathrm{mg}$.

c. Digoxin can be considered in patients with contraindications to beta blockers, in particular those with poor ejection fraction. There is some evidence that it increases atrial automaticity. It has a half-life of 38 to 48 hours in patients with normal renal function, significant potential toxicity, and a narrow therapeutic range. Levels must be monitored, particularly in patients with renal insufficiency. 
Many agents, including amiodarone, increase its serum level. Following chemical cardioversion, attempts should be made to minimize the number of rate-control agents used.

\section{Antiarrythmics:}

a. Metoprolol or diltiazem.

b. Ibutilide. It is given as a 1-mg intravenous bolus and repeated once if cardioversion fails to occur. Patients need to be monitored for a small but significant incidence of torsades de pointes that may be increased if given in conjunction with amiodarone.

c. Adenosine is helpful in the treatment of supraventricular tachycardia (SVT). (It should be avoided in transplant recipients, partially revascularized patients, and patients with atrial flutter).

\section{Anticoagulation:}

- Patients who remain in atrial fibrillation for more than 24 hours or have multiple sustained episodes over this period should be started on coumadin in the absence of contraindications.

- Heparin (intravenously, or low-molecularweight heparin subcutaneously) should be considered after 48 hours in patients with a history of stroke or transient ischemic attacks (TIAs) or who have a low ejection fraction.

\section{Right Ventricular Failure and Pulmonary Hypertension}

- Right ventricular failure can be a particularly difficult postoperative problem. It can be caused by perioperative ischemia or infarction or by acute increases in pulmonary vascular resistance (PVR).

- Preexisting pulmonary hypertension is caused commonly by left-sided heart failure, aortic stenosis, mitral valve disease, and pulmonary disease. Chronic pulmonary hypertension is characterized by abnormal increased vasoconstriction and vascular remodeling. ${ }^{6}$

\section{Drug therapy}

- Use of intravenous vasodilators [commonly, nitroprusside, nitroglycerin, tolazoline (PGI2), hydralazine, prostacyclin, adenosine, and nicardipine] to reduce PVR frequently is limited by systemic hypotension.
- Inotropes (typically milrinone, which also provides vasodilatation) can be beneficial. Since no intravenous vasodilator is selective for the pulmonary vasculature, topical administration can be significantly more effective in reducing PVR without causing systemic hypotension.

- Inhaled nitric oxide (NO) and PGI2 have comparable efficacy. They also can improve oxygenation by shunting blood to ventilated lung.

\section{B) BLEEDING, THROMBOSIS, TRANSFUSION STRATEGIES}

AND

One of the principal challenges of cardiac surgery is to achieve sufficient anticoagulation while the patient is supported on CPB without experiencing excessive bleeding postoperatively. Not surprisingly, patients undergoing off-pump CABG experience a significant reduction in postoperative bleeding and blood product transfusion requirements. ${ }^{7,8}$ Excessive bleeding and its complications, including blood product transfusions, cause significant morbidity and mortality.

Preoperative medications that can increase bleeding risk are common.

- Aspirin inhibits cyclooxygenase, reduces the synthesis of thromboxane A2(TXA2), and decreases platelet aggregation. ${ }^{9}$ Preoperative aspirin use modestly increases postoperative bleeding, ${ }^{10,11}$ but preoperative and early postoperative use (i.e., within 6 hours) is beneficial to outcome and ultimate survival.

- The glycoprotein

IIb/IIIa

inhibitors eptifibitatide and tirofiban are sufficiently short acting that surgery can be conducted safely despite recent exposure.

- Abciximab usually requires a 24- to 48-hour delay of surgery, if feasible, to avoid catastrophic bleeding. ${ }^{12}$

- Clopidogrel is a thienopyridine derivative that blocks platelet ADP P2Y12 receptors, inhibiting platelet activation by preventing ADPmediated responses, decreasing alpha-granule release, and lowering TXA2 and P-selectin expression with some anti-inflammatory effects. ${ }^{14}$ Cessation of clopidogrel is preferred 5 days preoperatively but is not advisable in patients with drug-eluting coronary artery stents.

\section{$\underline{\text { Postoperative Bleeding }}$}

In general, blood products should not be used to correct coagulation abnormalities unless the patient is bleeding 
significantly. All allogeneic blood products can contribute to transfusion-related lung injury and have other adverse effects.

- Protamine is indicated rarely and can increase bleeding. It binds the polyanionic glycosaminoglycan heparin and therefore neutralizing its effect. Its clinical application includes neutralizing the effect of heparin and delaying the absorption of subcutaneously administered insulin. Most clinicians use fixed dosing of protamine for neutralizing heparin which is based on the fixed protamine/ heparin ratio. The ratio used is 0.5 to $0.7 \mathrm{mg}$ of protamine for every 100 units of heparin given to the patient, giving at the rate of $25-50 \mathrm{mg} / \mathrm{min}$. Infusing protamine over $30 \mathrm{~min}$ may reduce the incidence of heparin rebound compared with administration over 5 min.

- Desmopressin (DDAVP) is a synthetic vasopressin analogue that acts by increasing the concentration of factor VIII(C) and von Willebrand factor, an important mediator of platelet adhesion. It is of benefit in patients with von Willebrand's disease and in patients with severe platelet dysfunction secondary to uremia. ${ }^{13}$ The prophylactic use of desmopressin $(0.3 \mu \mathrm{g} / \mathrm{kg}$ administered after bypass) is shown to decrease blood loss. DDAVP may have beneficial effects in certain subsets of patients including those with preexisting uremia.

- Recombinant factor VIIa (rFVIIa) is a drug approved for use in hemophiliacs that has been used successfully in arresting bleeding in patients with life-threatening hemorrhage after cardiac surgery.

- Aprotinin: When given before and after CPB, aprotinin significantly reduce post-operative bleeding and reduces the need for allogenic transfusions. It is the only drug approved by USFDA for allogenic transfusion. Possible mechanisms include antiinflammatory effects, inhibition of multiple proteases and antifibrinolytic effects.

- $\quad$ E-Amino caproic acid (EACA) or tranexamic acid are synthetic fibrinolytic inhibitors that acts by occupying the lysing binding sites on plasminogen and plasmin. This in turn, displaces these proteins from the lysine residues on fibrinogen and fibrin and interferes with the ability of plasmin to split fibrinogen.

Although, the routine use of fibrinolytic agent in open heart surgery is controversial, it has shown to result in modest reductions of bleeding after primary coronary bypass procedures.

\section{C) RESPIRATORY CARE}

$\underline{\text { Postoperative Pulmonary Pathophysiology }}$
- Following the introduction of CPB nearly 50 years ago, pulmonary complications were recognized and attributed to pulmonary vascular overload. ${ }^{15}$

- Increases are seen in the alveolar-arterial (A-a) gradient, pulmonary shunt fraction, and pulmonary edema, with a resulting decrease in compliance.

- Transfusion-related lung injury also may exacerbate lung dysfunction.

- Despite increased knowledge of the mechanisms of injury, to date, there have been no interventions with clear clinical benefit.

- Administration of methyl-prednisolone in a randomized, double-blind study significantly increased A-a gradient and shunt fraction, decreased both static and dynamic compliance, and delayed early extubation in a dose-dependent manner.

\section{$\underline{\text { Pleural Effusion }}$}

- Accumulation of fluid in the pleural space is common after cardiac surgery, particularly on the left side, and usually resolves with time and diuresis.

- Nonsteroidal anti-inflammatory agents are used to treat postpericardiotomy syndrome.

\section{$\underline{\text { Pneumonia }}$}

- Nosocomial pneumonias have high associated mortality, and the incidence of ventilator-associated pneumonia increases approximately $1 \%$ per day. ${ }^{16}$

- Gram-negative organisms are seen most commonly and should be the target of first-line empiric antibiotic coverage.

- Specific patient factors and culture results and sensitivities will further refine antibiotic therapy. ${ }^{17}$

\section{D) RENAL CARE}

Certain factors have been identified that place patients at risk of renal dysfunction in post bypass period. These include elevated preoperative serum creatinine, combined valve and bypass procedures and advanced age. Prolonged bypass times also may place patients at risk.

\section{Treatment}

Urine flow is diminished during bypass which results in hyperkalemia and accumulation of extracellular fluid.

- Furosemide (initial dose 5mg) or mannitol (0.5$1.0 \mathrm{mg} / \mathrm{kg}$ ) has been shown to increase urine output. 
- Fenoldopam in low doses $(0.05-0.1 \mu \mathrm{g} / \mathrm{kg} / \mathrm{min})$ increase renal blood flow.

\section{E) CNS CARE}

\section{$\underline{\text { Anesthetic depth }}$}

The modern assessment of anesthetic depth is important for proper management of the patient. If an increase in depth of anesthesia is needed, choice of agent will depends primarily on hemodynamic status of the patient.

- Small doses of opiods or benzodiazepine can be titrated incrementally in patient with stable hemodynamics.

- Use of nitrous oxide should be avoided after bypass for the risk of air embolism. It also elevates pulmonary arterial pressure in those with preexisting pulmonary hypertension and can depress RV function.

Neuromuscular blockade

Patients require additional neuromuscular relaxation in post-bypass period. The main objective is to prevent shivering which in some circumstances can increase $\mathrm{O}_{2}$ consumption by $500 \%$. d-tubocurarine can be used in this cases.

\section{F) POSTOPERATIVE PAIN AND SEDATION MANAGEMENT}

Managing postoperative pain and agitation are paramount in caring for the postoperative cardiac surgery.

Pain represents response to nociceptor stimulation from the surgical intervention.

Table 3: Analgesics and their doses.

\begin{tabular}{|c|c|c|c|}
\hline Analgesics & $\begin{array}{l}\text { Intravenous } \\
\text { loading dose }\end{array}$ & Maintenance dose & Special considerations \\
\hline Fentanyl & $0.5-3.0 \mu \mathrm{g} / \mathrm{kg}$ & $1-4 \mu \mathrm{g} / \mathrm{kg}$ & $\begin{array}{c}\text { May cause bradycardia, tachyphylaxis to } \\
\text { infusion }\end{array}$ \\
\hline Morphine & $0.08-0.12 \mathrm{mg} / \mathrm{kg}$ & $\begin{array}{c}0.03 \mathrm{mg} / \mathrm{kg} \text { every } 10 \\
\mathrm{~min}\end{array}$ & $\begin{array}{l}\text { Histamine release. Metabolites accumulate in } \\
\text { renal failure }\end{array}$ \\
\hline Ketorolac & $15-30 \mathrm{mg}$ & $\begin{array}{l}15 \text { mg IV every } 6 \\
\text { hours }\end{array}$ & Caution in renal failure, coagulopathy \\
\hline Hydromorphone & $0.02 \mathrm{mg} / \mathrm{kg}$ & $\begin{array}{l}25-50 \mu \mathrm{g} / \mathrm{kg} \text { every } \\
10 \mathrm{~min}\end{array}$ & No metabolites in renal failure \\
\hline Meperidine & $1.0-1.5 \mathrm{mg} / \mathrm{kg}$ & $\begin{array}{l}0.3 \mathrm{mg} / \mathrm{kg} \text { every } 10 \\
\mathrm{~min}\end{array}$ & $\begin{array}{l}\text { May cause tachycardia. Avoid with MAO } \\
\text { inhibitors. Metabolites may accumulate in } \\
\text { renal failure and may reduce seizure } \\
\text { threshold. }\end{array}$ \\
\hline Butorphanol & $0.02-0.04 \mathrm{mg} / \mathrm{kg}$ & $\begin{array}{l}0.01 \mathrm{mg} / \mathrm{kg} \text { every } 10 \\
\mathrm{~min}\end{array}$ & Mixed agonist/ antagonist \\
\hline Nalbuphine & $0.08-0.15 \mathrm{mg} / \mathrm{kg}$ & $\begin{array}{c}0.03 \mathrm{mg} / \mathrm{kg} \text { every } 10 \\
\mathrm{~min}\end{array}$ & Mixed agonist/ antagonist \\
\hline Codeine & $0.5-1 \mathrm{mg} / \mathrm{kg}$ & $\begin{array}{c}1 / 3 \text { of total bolus } \\
\text { every } 15 \mathrm{~min}\end{array}$ & Nausea \\
\hline
\end{tabular}

\section{A. Systemic opioids:}

- It is useful to discern the type, quality, and location of pain before administering an analgesic agent.

- Commonly used opioids include fentanyl, morphine, hydromorphone, and meperidine.

- These drugs work through the $\mu$ receptor mechanism to provide analgesia.
- $\quad$ Given table lists (Table 3) commonly used analgesic agents for postoperative pain along with loading and maintenance dosing.

\section{B. Intrathecal opioids:}

- This route constitutes an alternative to systemic opioids.

- Intrathecal opioids can facilitate early extubation and discharge from an ICU without compromising pain 
control or increasing likelihood of myocardial ischemia.

- Intrathecal morphine may be useful in attenuating the postsurgical stress in CABG patients as measured by plasma cortisol and epinephrine concentrations. ${ }^{18}$

\section{Nonsteroidal anti-inflammatory drugs (NSAIDs):}

- A concern with NSAIDs is their inhibition of platelet function and the potential for increased bleeding.

- $\quad$ NSAIDs also have been considered a poor choice after cardiac surgery due its tendency to induce gastric ulcer formation and impaired renal function and advised to exclude the use of NSAIDs in the postoperative cardiac surgery patients. ${ }^{19}$

\section{G) METABOLIC CONSIDERATION}

\section{a) Hypokalemia:}

- Treatment is varied depending upon the severity of hypokalemia.

- In most instances, intravenous infusion of potassium chloride $\mathrm{KCl}$ upto $10 \mathrm{mEq} /$ hour is effective.

- In life threatening condition, potassium may be administered at rate of $20 \mathrm{mEq} /$ hour with continuous cardiac monitoring.

\section{b) Hyperkalemia:}

Hyperkalemia may persist in the post-bypass period but generally resolve spontaneously without intervention.

Treatment require in case of moderate hyperkalemia $(\mathrm{K}$ level between 6.0 and $7.0 \mathrm{mEq} / \mathrm{L}$ ).

It includes:

\section{Diuresis}

2. Sodium bicarbonate, $1-2 \mathrm{mEq} / \mathrm{kg}$ in children and one ampoule $(44.6 \mathrm{mEq})$ in adults.

3. Infusion of dextrose and insulin, $1-2 \mathrm{~g}$ glucose/ $\mathrm{kg}$ with 0.3 units/gm of glucose in children; $25 \mathrm{~g}$ of glucose and 10 units of regular insulin in adults.

4. Calcium, $20 \mathrm{mg} / \mathrm{kg}$ calcium gluconate over a 5 minutes period for children and 500-1000mg of calcium chloride for adults.

\section{c) Hypocalcemia:}

- Sequestration of calcium occurs with administration of a large volume of blood that contain the chelating agent citrate. Severe hypocalcemia results in myocardial depression and vasodilation.

- Calcium may be administered as $10 \%$ calcium chloride (272 mg of elemental calcium) in a dose of $5-10 \mathrm{mg} / \mathrm{kg}$.

\section{d) Hypomagnesemia:}

- Etiologic factors include loss of cation in the extracorporeal circuit and redistribution of magnesium to the other body stores.

- England and colleagues ${ }^{20}$ suggested that those receiving $2 \mathrm{~g}$ of $\mathrm{MgCl}_{2}$ after termination of bypass surgery had lower incidence of postoperative ventricular dysarrhythmia and increased cardiac index in the early postoperative period.

H) RELEVANT COMPLICATIONS

POSTOPERATIVE

$\underline{\text { Infections }}$

\section{Nosocomial infections}

- Between 10 and $20 \%$ of cardiac surgery patients develop a nosocomial infection. Infections may be related to the surgical wound, lung, urinary tract, invasive lines or devices, or the gastrointestinal tract.

- Prolonged mechanical ventilation is associated with nosocomial pneumonia. These are second only to urinary tract infection in frequency and carry the highest mortality rate. ${ }^{21}$

- The most common pathogens are staphylococcus aureus (12\%), coagulase-negative staphylococci (11\%), Candida albicans (11\%), pseudomonas aeruginosa (10\%), and enterococcus spp.

- Other infections include delayed sternal closure/sternal infection, sepsis/septic shock.

Treatment includes

Identification of pathogens using culture sensitivity.

Strict antibiotic coverage using $3^{\text {rd }}$ generation cephalosporin.

\section{$\underline{\text { Nutritional Intervention }}$}

- Preoperative debilitated or cachectic patients (i.e., more than $10 \%$ weight loss over 6 months) with albumin levels of less than $3.5 \mathrm{~g} / \mathrm{dL}^{22}$ are exceptionally prone to complications, such as infections, following surgery. 
- Postoperative patients have accelerated catabolic protein loss, usually requiring 25 to $40 \mathrm{kcal} / \mathrm{kg}$ per day.

- Advances in immunonutritional pharmacology (i.e., arginine, glutamine and n-3 fatty acids) in complex postoperative cardiac surgery patients may have a defined role in the future. ${ }^{23-25}$

\section{CONCLUSION}

In cardiac surgical intensive care, early recognition of an impending disaster and initiation of treatment increase patient's chances of survival and at the very least prevent further complications. This can be ensured by systematical approach.

The body consists of different systems and all of them integrate and interact with each other. If there is something wrong with one component, one should expect some problems in the other systems. The scope of cardiac surgical critical care includes prediction and prevention of problems as well as investigation and intervention. However, preventing deterioration is more effective than attempting salvage at a later stage. In addition, prompt simple actions can save lives and prevent complications. Therefore, the best critical care is simple and preventive. Late, heroic interventions generally are less successful.

\section{REFERENCES}

1. Konuralp C, Idiz M. Systematic approach on postoperative care of the cardiac surgical patients. Anadolu Kardiyol Derg 2003;3:156-61.

2. Shanmugam G. Vasoplegic syndrome--The role of methylene blue. Eur J Cardiothorac Surg 2005;28:705-10.

3. Faber P, Ronald A, Millar BW. Methylthioninium chloride: pharmacology and clinical applications with special emphasis on nitric oxide mediated vasodilatory shock during cardiopulmonary bypass. Anaesthesia 2005;60:575-87.

4. Grose R, Strain J, Greenberg M, et al. Systemic and coronary effects of intravenous milrinone and dobutamine in congestive heart failure. J Am Coll Cardiol 1986;7:1107-13.

5. Maisel WH, Rawn JD, Stevenson WG. Atrial fibrillation after cardiac surgery. Ann Intern Med 2001;135:1061-73.

6. Martin KB, Klinger JR, Rounds SI. Pulmonary arterial hypertension: New insights and new hope. Respirology 2006;11:6-17.

7. Puskas JD, Williams WH, Duke PG, et al. Off-pump coronary artery bypass grafting provides complete revascularization with reduced myocardial injury, transfusion requirements, and length of stay: A prospective, randomized comparison of two hundred unselected patients undergoing off-pump versus conventional coronary artery bypass grafting. J Thorac Cardiovasc Surg 2003;125:797-808.
8. Gerrah R, Snir E, Brill A, et al. Platelet function changes as monitored by cone and platelet analyzer during beating heart surgery. Heart Surg Forum 2004; 7:E191-5.

9. Frangos SG, Chen AH, Sumpio B. Vascular drugs in the new millennium. J Am Coll Surg 2000;191:76-92.

10. Ferraris VA, Ferraris SP, Joseph O, et al. Aspirin and postoperative bleeding after coronary artery bypass grafting. Ann Surg 2002;235:820-7.

11. Ferraris VA, Ferraris SP, Lough FC, et al. Preoperative aspirin ingestion increases operative blood loss after coronary artery bypass grafting. Ann Thorac Surg 1988;45:71-4.

12. Silvestry SC, Smith PK. Current status of cardiac surgery in the abciximab-treated patient. Ann Thorac Surg 2000;70(2 Suppl):S12-9.

13. Cattaneo M, Harris AS, Stromberg U, et al. The effect of desmopressin on reducing blood loss in cardiac surgery: a meta-analysis of double-blind, placebo-controlled trials. Thromb Haemost 1995;74:1064-70.

14. Baggish AL, Sabatine MS. Clopidogrel use in coronary artery disease. Expert Rev Cardiovasc Ther 2006;4:7-15.

15. Kolff WJ, Effler DB, Groves LK, et al. Pulmonary complications of open-heart operations: Their pathogenesis and avoidance. Cleve Clin Q 1958;25:65-83.

16. Fagon JY, Chastre J, Domart Y, et al. Nosocomial pneumonia in patients receiving continuous mechanical ventilation: Prospective analysis of 52 episodes with use of a protected specimen brush and quantitative culture techniques. Am Rev Respir Dis 1989;139:877-84.

17. Fischer UM, Weissenberger WK, Warters RD, et al. Impact of cardiopulmonary bypass management on postcardiac surgery renal function. Perfusion 2002;17:401-6.

18. Hall R, Adderley N, MacLaren C, et al. Does intrathecal morphine alter the stress response following coronary artery bypass grafting surgery? Can J Anesth 2000;47:463-6.

19. Hynninen MS, Cheng DC, Hossain I, et al. Nonsteroidal anti-inflammatory drugs in treatment of postoperative pain after cardiac surgery. Can $\mathbf{J}$ Anesth 2000;47:1182-7.

20. Montes FR, Sanchez SI, Girlado JC, et al. The lack of benefit of tracheal extubation in the operating room after coronary artery bypass surgery. Anesth Analg 2000;91:776-80.

21. Cross JT Jr, Campbell GD Jr. Therapy of nosocomial pneumonia. Med Clin North Am 2001;85:1583-94.

22. Carney DE, Meguid MM. Current concepts in nutritional assessment. Arch Surg 2002;137:42-5.

23. Kendler BS. Supplemental conditionally essential nutrients in cardiovascular disease therapy. J Cardiovasc Nurs 2006;21:9-16. 
24. Heyland DK, Novak F, Drover JW, et al. Should immunonutrition become routine in critically ill patients? A systematic review of the evidence. JAMA 2001;286:944-53.
25. Alexander JW. Nutritional pharmacology in surgical patients. Am J Surg 2002;183:349-52.

doi: 10.5455/2319-2003.ijbcp003312

Cite this article as: Baig MS, Sonkusare K, Gade PR. Drugs used in postoperative care of bypass surgeryan overview. Int J Basic Clin Pharmacol 2012;1:1409. 